\title{
3 Research Square

\section{Stage-Dependent Niche Segregation: Insights From a Multi-Dimensional Approach of Two Sympatric Sibling Seabirds}

\author{
Aymeric Fromant ( $\square$ afromant@deakin.edu.au ) \\ Deakin University https://orcid.org/0000-0002-3024-7659
}

John P.Y. Arnould

Deakin University

Karine Delord

CEBC: Centre d'Etudes Biologiques de Chize

Grace J Sutton

Deakin University

Alice Carravieri

CEBC: Centre d'Etudes Biologiques de Chize

Paco Bustamante

LIENSs: Littoral Environnement et Societes

Colin M. Miskelly

Museum of New Zealand Te Papa Tongarewa

Akiko Kato

CEBC: Centre d'Etudes Biologiques de Chize

Maud Brault-Favrou

LIENSs: Littoral Environnement et Societes

Yves Cherel

CEBC: Centre d'Etudes Biologiques de Chize

Charles-André Bost

CEBC: Centre d'Etudes Biologiques de Chize

\section{Research Article}

Keywords: Niche partitioning, foraging and diving behaviour, trophic niche, Pelecanoides

Posted Date: December 3rd, 2021

DOI: https://doi.org/10.21203/rs.3.rs-1052090/v1 
License: (c) (i) This work is licensed under a Creative Commons Attribution 4.0 International License. Read Full License 


\section{Abstract}

Niche theory predicts that to reduce competition for the same resource, sympatric ecologically similar species should exploit divergent niches and segregate in one or more dimensions. Seasonal variations in environmental conditions and energy requirements can influence the mechanisms and the degree of niche segregation. However, studies have overlooked the multi-dimensional aspect of niche segregation over the whole annual cycle, and key facets of species co-existence still remain ambiguous. The present study provides insights into the niche use and partitioning of two morphologically and ecologically similar seabirds, the common (CDP, Pelecanoides urinatrix) and the South Georgian diving petrels (SGDP, $P$. georgicus). Using phenology, at-sea distribution, diving behavior and isotopic data (during the incubation, chick-rearing and non-breeding periods), we show that the degree of partitioning was highly stage-dependent. During the breeding season, the greater niche segregation during chick-rearing than incubation supported the hypothesis that resource partitioning increases during energetically demanding periods. During the post breeding period, while the observed species-specific latitudinal differences were expected, CDP and SGDP also migrated in very divergent directions. This may indicate the implication of processes other than inter-species niche competition. Our results demonstrate the importance of integrative approaches combining concepts and techniques from different fields to better understand the co-existence of ecologically similar species. The stage-dependent and context-dependent niche segregation highlights the need for whole-year and multiple-site studies of niche partitioning of sympatric species. This is particularly relevant in order to fully understand the short and long-term effects of ongoing environmental changes on species distributions and communities.

\section{Introduction}

The concept of niche is central in ecology, defined as a hyper-volume within an N-dimensional niche space (Hutchinson 1957), and has found important applications in fundamental ecology, evolution, species management and conservation (Putman and Flueck 2011). Niche theory predicts that in order to limit the competition for the same resource, sympatric ecologically similar species should exploit divergent niches and segregate in one or more dimensions (MacArthur 1958). Niche segregation has been observed in a diverse range of taxa including plants (Monson et al. 1983), invertebrates (Finke and Snyder 2008) and vertebrates (Latham 1999), in both terrestrials and marine environments (Ainley et al. 2009). Investigating niche segregation is essential to gather knowledge about how and why species coexist, especially for sibling species. In addition, it is also of particular relevance to evaluate the species' ability to adjust the characteristics of its niche hyper-volumes over time and space. This step is an essential prerequisite for assessing a species' capacity to buffer current and future environmental changes.

Seabirds are a particularly good model taxon to study niche segregation as they aggregate in large mixed-species populations in spatially restrained breeding and foraging habitats (Ainley et al. 2009). Although there is an ongoing interest in niche segregation in seabirds, the strong three-dimensional aspect of the marine environment challenges our understanding of the underlying mechanisms driving 
niche partitioning. In particular, segregation in seabirds can occur temporally (daily and seasonally; Granroth-Wilding and Phillips 2019), spatially (in both horizontal and vertical dimensions; Kokubun et al. 2016), and trophically (Cherel et al. 2005). However, very few studies have investigated the niche partitioning in more than two dimensions (Navarro et al. 2015), thereby complicating the possibility to distinguish the mechanisms leading to segregation.

High latitude seabirds typically experience varying influences of extrinsic and intrinsic factors throughout their annual cycle. Strong seasonal variations in oceanographic conditions and prey availability (extrinsic factors) can influence the patterns of niche partitioning, as trophic segregation might highlight competition for limited food resources, while a superabundance of prey enables overlapping niches (Barger and Kitaysky 2012). The degree of niche segregation might change according to the variation in energy requirements (intrinsic factors) related to the different constraints of each breeding stage and moult (Calado et al. 2018). During the breeding season, niche partitioning is likely to be at its maximum during the chick-rearing period, when offspring provisioning adds on to adults self-supplying (Barger et al. 2016). Similarly, outside the breeding season, the high energetic demand of the moult may increase interspecies competition during this critical and unfavorable period (Dunn et al. 2019). However, most niche segregation studies have focused on one stage of the annual cycle at a time, mainly during the breeding season when seabirds are easily accessible. Therefore, key facets of species co-existence still remain ambiguous. Clearly, more attention is needed concerning the description of niche segregation throughout the entire annual cycle.

The Southern Ocean hosts a wide range of sympatric seabirds with various physiological and ecological adaptations to the marine environment. However, conventional foraging studies (at-sea movements and diving behaviour) have focused mainly on larger species mostly because of technological and practical reasons. In addition, the primary investigation of niche segregation in such studies revolves around the flying characteristics of albatrosses (Phillips et al. 2004), or the diving capacities of penguins (Wilson 2010). Among seabirds of the Southern Ocean, diving petrels (Pelecanoides spp.) are unique in their diving (Navarro et al. 2014) and flying abilities (Fromant et al. 2021). In the five recognized species of diving petrels (Fischer et al. 2018; Marchant and Higgins 1990), the common diving petrel (CDP, $P$. urinatrix) and the South Georgian diving petrel (SGDP, P. georgicus) have a circumpolar distribution and breed sympatrically in several archipelagos of the Southern Ocean (Fig. 1; Marchant and Higgins 1990). These two sibling species have been shown to locally segregate by foraging at different depths (Navarro et al. 2013; Bocher et al. 2000) and habitats (Navarro et al. 2015), or feeding on different prey (Ridoux 1994; Reid et al. 1997; Bocher et al. 2000). However, site-specific and stage-specific inconsistencies preclude a global picture of their segregation. In particular, the lack of investigations over the whole annual cycle, combined to the limited number of dimensions explored, complicate our ability to fully describe and understand the niche segregation of these two sympatric species.

We investigated the niche segregation between CDP and SGDP at Kerguelen Islands, by quantifying the hyper-volume differences of these two morphologically and ecologically similar species throughout their whole annual cycle. Using an integrative approach combining phenology, at-sea movement, diving, 
accelerometer, and isotopic data, we addressed three main questions: (1) do CDP and SGDP differ in their timing of breeding, distribution, diving behaviour and isotopic niche?; (2) does the degree of niche segregation vary throughout their annual cycle?; and (3) are the processes leading to niche partitioning similar during the pre-breeding, incubation, chick-rearing and post-breeding periods?

Based on previous trophic and isotopic analysis (Bocher et al. 2000) we predicted that niche segregation between the two species is mostly driven by 1 ) differences in diving behavior, spatial partitioning and diet during the breeding period, and 2) spatial partitioning during the post-breeding period (similarly to what was observed among other small-sized procellariiform species; Quillfeldt et al. 2015). Since niche segregation can be more pronounced during energetically challenging periods (Barger et al. 2016), we also predicted stronger behavioural and/or trophic differences during the chick-rearing period, and during the first months of the post-breeding period, when adults renew their plumage.

\section{Methods}

Fieldwork was conducted at Kerguelen Islands, Southern Indian Ocean. A total of 121 CDP and 105 SGDP were tracked across five consecutive annual cycles (see details of year- and stage-specific in Table S1). The annual cycle was divided into four distinct periods: the incubation and chick-rearing periods during the breeding season, and the post-breeding migration (from departure to return to the colony) and prebreeding period (from return to the colony to the start of the breeding season) during the non-breeding season. Although both species breed in sympatry on some islands of the archipelago, for logistical and practical reasons, the study colonies we used were located on two islands $6 \mathrm{~km}$ apart within the Golfe du Morbihan (semi-closed embayment): CDP at lle Mayes ( $\left.49^{\circ} 28^{\prime} \mathrm{S}, 69^{\circ} 57^{\prime} \mathrm{E}\right)$ and SGDP at lle aux Cochons $\left(49^{\circ} 47^{\prime} \mathrm{S}, 70^{\circ} 05^{\prime} \mathrm{E}\right)$. Both species breed in burrows and the nest chamber was accessed by an artificial entrance covered with a removable stone lid. This access system reduced the disturbance of the natural tunnel and facilitated rapid access to the birds which were captured in the nest burrow for all procedures (Fromant et al. 2020a).

To obtain an overview of the breeding phenology of both species, chicks were monitored and measured during the breeding season 2015-2016 (CDP $=25$, SGDP $=27)$, and hatching dates were determined using the method described by Eizenberg et al. (2021). The wing length-age relationship was used as a proxy to determine the hatching date (see Supplementary materials for more details).

To evaluate the at-sea distribution and diving behaviour during both the incubation and chick-rearing periods, miniature GPS ( 2.0 g; nanoFix-GEO, Pathtrack Ltd, Otley, United Kingdom), time-depth recorder (TDR; 2.7 g; Cefas G5, Cefas Technology Ltd, Lowestoft, United Kingdom) and depth-accelerometer (4.0 g; AxiDepth, TechnoSmArt Ltd, Italy) data loggers were deployed using adhesive water proof tape (Tesa 4651, Beiersdorf AG, Germany) on two central tail feathers (for GPS and TDR) or on back feathers (for accelerometers). The GPS loggers were programmed to record locations at $10 \mathrm{~min}$ and 5 min interval during the incubation and chick-rearing periods, respectively. Both TDRs and depth-accelerometer data loggers were programmed to record pressure and hence dive depth $( \pm 5 \mathrm{~cm})$, and temperature $\left( \pm 0.1^{\circ} \mathrm{C}\right)$ 
every $1 \mathrm{~s}$. In addition, accelerometers measured tri-axial body acceleration at $25 \mathrm{~Hz}$. Because of the small size of the species $(<180 \mathrm{~g})$, only one type of device was deployed on each individual at a time. The total mass of logger attachments was between 1.5-2.5\% of body weight for CDP (120-180 g), and 2.0-2.9\% for SGDP (110-150 g).

To determine the at-sea distribution of CDP and SGDP during the non-breeding period (post-breeding migration and pre-breeding period), adult birds were equipped with leg-mounted GLS (Migrate Technology, model C65, United Kingdom) ( $1.1 \pm 0.1 \%$ of body mass). Breeding individuals were equipped at the end of the breeding season and were recaptured during the following breeding season.

Stable isotope ratios of carbon $\left(\delta^{13} \mathrm{C}\right)$ and nitrogen $\left(\delta^{15} \mathrm{~N}\right)$ in whole blood and body feathers were used as proxies of the foraging habitat and diet/trophic level, respectively. Specifically, isotopic values of whole blood (hereafter blood) reflect dietary integration of approximately two to four weeks, while body feathers reflect dietary intake when they were synthesized (Cherel et al. 2000). Blood (0.2 mL) was collected from the brachial vein at recapture for stable isotope analysis and sexing. Sex was determined by DNA analysis (Laboratoire Analyses Biologiques, CEBC, France). Individuals were weighed ( \pm 2 g; Pesola), and bill, tarsus ( $\pm 0.1 \mathrm{~mm}$; Vernier calipers) and wing length ( $\pm 1 \mathrm{~mm}$; ruler) were measured.

All data processing is detailed in the supplementary materials. Statistical analyses were conducted within the R statistical environment (R Core Team 2020). Effects of species, stage, and year (fixed effects) on foraging and diving parameters were investigated by generating multiple Generalized Linear Mixed Models (GLMMs) using the package glmmADMB (Bolker et al. 2012). Individual was added as a random effect. To investigate factors influencing diving behavior (dive depth, dive duration and mean VeDBA per dive), Generalized Additive Mixed Models (GAMMs) were fitted using the mgcv package (Wood 2018). Models were ranked based on their Akaike's Information Criterion (AIC) and were checked to ensure normality and homoscedasticity of residuals (Zuur et al. 2010) before further statistical analyses. Posthoc tests were conducted using non-parametric statistics (Kruskal-Wallis and Mann-Whitney Utests) when parametric test assumptions of normality were unmet. To investigate at-sea spatial segregation, the percentage overlap in foraging distribution were estimated using Bhattacharyya's Affinity (BA) index (Fieberg and Kochanny 2005) using the adehabitatHR R package (Calenge 2006). BA index (0 signifying no overlap in UDs, and 1 = complete overlap) is a statistical measure for the degree of similarity amongst UDs, and the amount of space-use shared among species. The isotopic niche position and width were compared between species and breeding stages using the ellipse area-based metrics of the SIBER package (Jackson et al. 2011).

\section{Results}

All the morphological measurements, trip parameters and stable isotopes results were compared between sex for both species (Table S2). Because of the limited inter-sex differences for both CDP and SGDP, data were pooled in all subsequent statistical analyses. Similarly, because of the small inter-annual variations in foraging behavior and stable isotope values, data were pooled by species and stage. 


\section{Morphological differences}

Morphological differences between CDP and SGDP were investigated using measurements of body mass, wing length, tarsus length, and bill length of adult breeding individuals. Although all the measurements overlapped between the two species (Fig. 2), CDP had significantly larger body mass, and longer wing, tarsus and bill lengths (Table S3). The difference between the two species was emphasized by CDP being proportionately heavier than SGDP (Fig. 2), resulting in a higher wing load (ratio body mass / wing length, $\mathrm{CDP}=1.16 \pm 0.08 ; \mathrm{SGDP}=1.08 \pm 0.08$; $t$-tests: $t_{60.001}=4.146, P<0.001$ ).

\section{Phenology}

The average laying date of CDP (28-Nov \pm 10 ; ranging from 15-Nov to 18-Dec) was estimated to be 18 days later than SGDP (10-Nov \pm 10 ; ranging from 27-Oct to 12-Dec; $t$-tests: $t_{47.238}=-6.291, P<0.001$ ). Similarly, owing to the longer incubation and chick-rearing duration period for CDP, the mean hatching date of CDP (22-Jan \pm 10$)$ was estimated to occur on average 26 days later than SGDP (27-Dec $\pm 10 ; t$ tests: $\left.t_{47.238}=-9.082, P<0.001\right)$, and the fledging date was 32 days later for $\operatorname{CDP}(16-M a r \pm 10)$ than $\operatorname{SGDP}\left(13-F e b \pm 10\right.$; $t$-tests: $\left.t_{47.238}=-11.176, P<0.001\right)$. The incubation period of CDP overlapped during $29 \mathrm{~d}$ of the SGDP incubation period (62\% overlap), and also $26 \mathrm{~d}$ with the SGDP chick-rearing period (55\% overlap) (Fig. 1).

\section{Spatial segregation: at-sea distribution and diving behavior}

During the incubation period, both CDP and SGDP travelled 200-400 km south of Kerguelen, along the shelf-slope of the Kerguelen Plateau (Fig. 3A), overlapping in their foraging distribution (BA indices for $50 \%$ UDs $=0.62$ ). Although, one CDP individual undertook a short foraging trip within the Golfe du Morbihan, there was no significant difference for offshore trips between both species, neither in duration (CDP $=45 \pm 1 \mathrm{~h}$; SGDP $=45 \pm 24 \mathrm{~h}$; Mann-Whitney $U$ test: $U=3, P=0.700$ ), nor in distance travelled (CDP $=777 \pm 154 \mathrm{~km} ;$ SGDP $=653 \pm 98 \mathrm{~km}$; Mann-Whitney $U$ test: $U=7, P=0.400)$ or maximum distance from the colony (CDP $=331 \pm 71 \mathrm{~km}$; SGDP $=322 \pm 108 \mathrm{~km}$; Mann-Whitney $U$ test: $U=14, P=0.762)$. Similarly, CDP and SGDP exhibited comparable dive characteristics during the incubation period (Table 1; Fig. 4). Both species were diving to similar depths (Mann-Whitney $U$ test: $U=14, P=0.808$ ), and for similar durations (Mann-Whitney $U$ test: $U=24, P=0.214$ ). Nonetheless, CDP and SGDP differed in their mean VeDBA values. While diving at a similar depth, SGDP exhibited higher mean VeBDA values than CDP (Fig. $S 1)$, for both dive duration $\left(F_{6.020}=178.60, P<0.01\right)$ and depth $\left(F_{6.215}=165.03, P<0.01\right)$, indicating they were more active underwater than CDP. 
Table 1

Overall tracking data and whole blood stable isotope values (mean \pm SD) of common and SouthGeorgian diving petrels during the incubation and chick-rearing periods at Kerguelen Islands. For each parameter, values not sharing the same superscript letter ( $a$, $b$ or $c$ ) are significantly different (MannWhitney Utest: $P<0.05)$.

\begin{tabular}{|c|c|c|c|c|}
\hline & \multicolumn{2}{|c|}{ Common diving petrels } & \multicolumn{2}{|c|}{$\begin{array}{l}\text { South-Georgian diving } \\
\text { petrels }\end{array}$} \\
\hline & Incubation & $\begin{array}{l}\text { Chick- } \\
\text { rearing }\end{array}$ & Incubation & Chick-rearing \\
\hline $\begin{array}{l}\text { GPS data } \\
\text { ( } \mathrm{N} \text { individuals; } \mathrm{n} \text { trips) }\end{array}$ & $N=6 ; n=6$ & $\begin{array}{l}N=31 ; n= \\
39\end{array}$ & $\begin{array}{l}N=6 ; n= \\
6\end{array}$ & $\begin{array}{l}N=37 ; n= \\
46\end{array}$ \\
\hline Trip duration (h) & $40 \pm 10^{a}$ & $19 \pm 1^{\mathrm{b}}$ & $45 \pm 24^{\mathrm{ac}}$ & $28 \pm 10^{c}$ \\
\hline Total distance travelled $(\mathrm{km})$ & $506 \pm 388^{a}$ & $84 \pm 23^{b}$ & $653 \pm 98^{a}$ & $535 \pm 115^{a}$ \\
\hline $\begin{array}{l}\text { Maximum distance from colony } \\
(\mathrm{km})\end{array}$ & $227 \pm 171^{\mathrm{ab}}$ & $19 \pm 10^{c}$ & $\begin{array}{l}322 \pm \\
108^{\mathrm{a}}\end{array}$ & $208 \pm 68^{b}$ \\
\hline $\begin{array}{l}\text { Dive data } \\
\text { ( } \mathrm{N} \text { individuals; } \mathrm{n} \text { trips) }\end{array}$ & $N=7 ; n=7$ & $\begin{array}{l}N=12 ; n= \\
21\end{array}$ & $\begin{array}{l}N=4 ; n= \\
4\end{array}$ & $\begin{array}{l}N=11 ; n= \\
13\end{array}$ \\
\hline Dive depth (m) & $6.5 \pm 0.5^{\mathrm{a}}$ & $15.2 \pm 3.2^{b}$ & $6.6 \pm 0.8^{a}$ & $6.1 \pm 2.6^{a}$ \\
\hline Dive duration (s) & $28 \pm 3^{a}$ & $44 \pm 6^{b}$ & $25 \pm 3^{\mathrm{ac}}$ & $23 \pm 5^{c}$ \\
\hline $\begin{array}{l}\text { Time activity budget } \\
\text { ( } \mathrm{N} \text { individuals; } \mathrm{n} \text { trips) }\end{array}$ & $N=7 ; n=7$ & $\begin{array}{l}N=10 ; n= \\
19\end{array}$ & $\begin{array}{l}N=4 ; n= \\
4\end{array}$ & $N=6 ; n=8$ \\
\hline Flying (\%) & $\begin{array}{l}53.4 \pm \\
14.0^{\mathrm{ab}}\end{array}$ & $50.9 \pm 12.9^{b}$ & $33.0 \pm 4.8^{\mathrm{a}}$ & $49.2 \pm 19.0^{\mathrm{ab}}$ \\
\hline Resting (\%) & $\begin{array}{l}27.5 \pm \\
13.5^{\mathrm{ab}}\end{array}$ & $25.6 \pm 12.9^{b}$ & $49.9 \pm 4.2^{\mathrm{a}}$ & $33.4 \pm 18.7^{\mathrm{ab}}$ \\
\hline Diving (\%) & $19.1 \pm 5.1^{\mathrm{ab}}$ & $23.5 \pm 4.7^{b}$ & $17.1 \pm 3.2^{\mathrm{a}}$ & $17.4 \pm 3.3^{\mathrm{a}}$ \\
\hline Stable isotopes ( $\mathrm{N}$ individuals) & $N=46$ & $N=50$ & $N=22$ & $N=51$ \\
\hline Whole blood $\delta^{13} \mathrm{C}(\% \circ)$ & $-21.3 \pm 2.1^{\mathrm{a}}$ & $-18.4 \pm 1.2^{\mathrm{b}}$ & $\begin{array}{l}-23.3 \pm \\
0.3^{c}\end{array}$ & $-22.7 \pm 0.4^{d}$ \\
\hline Whole blood $\delta^{15} \mathrm{~N}(\%)$ & $9.2 \pm 1.2^{\mathrm{a}}$ & $11.0 \pm 1.0^{\mathrm{b}}$ & $9.0 \pm 0.3^{a}$ & $8.4 \pm 0.4^{c}$ \\
\hline
\end{tabular}

During the chick-rearing period, CDP and SGDP strongly segregated in their at-sea distribution, dive depth, and dive duration (Table 1; Fig. 3B and C). While SGDP continued to forage at a distance, along the shelfslope of the Kerguelen Plateau, CDP foraged inshore, within the Golfe du Morbihan. This switch in 
foraging habitat by CDP resulted in a decrease in the prospecting distance. This was associated with an increased diving effort for CDP, with birds diving significantly deeper (Mann-Whitney $U$ test: $U=2, P<$ 0.001) and longer (Mann-Whitney $U$ test: $U=1, P<0.001$ ) than SGDP at that time (Table 1; Fig. S2). The relationship between dive bottom duration, post-dive duration and dive depth indicated divergent relative dive efficiencies (Fig. 4D), with CDP being more efficient divers than SGDP with increasing depths.

During the post-breeding period, CDP and SGDP differed markedly in their at-sea distributions. Directly after the breeding season (1-5 days after the last burrow attendance), both species migrated in divergent directions (2 000-5 $000 \mathrm{~km}$ apart; Fig. 3D). The maximum migration range was significantly larger for SGDP (Mann-Whitney $U$ test: $U=8, P=0.016$; Table 2), as well as the total distance travelled (MannWhitney $U$ test: $U=8, P=0.006$ ) and the total duration of migration (Mann-Whitney $U$ test: $U=8, P=$ 0.002). After returning from migration (late September for CDP; early October for SGDP), both species spent most of the pre-breeding period north-east of the Kerguelen Plateau within $1000 \mathrm{~km}$ of their colony locations (Fig. 3E). During this period, the at-sea distribution of CDP and SGDP completely overlapped (BA indices for $50 \%$ UDs $=0.94$ ). 
Table 2

Trip parameters and feather stable isotope values (mean \pm SD) of the post-breeding migration of common and South-Georgian diving petrels from Kerguelen Islands. Due to a malfunction, all the GLS deployed in 2015-16 stopped recording 3-6 months after deployment.

\begin{tabular}{|c|c|c|c|c|c|}
\hline & \multicolumn{2}{|c|}{$\begin{array}{l}\text { Common diving } \\
\text { petrels }\end{array}$} & \multicolumn{2}{|c|}{$\begin{array}{l}\text { South-Georgian } \\
\text { diving petrels }\end{array}$} & \multirow{2}{*}{$\begin{array}{l}\text { Mann-Whitney U Test } \\
\text { (CDP 2017-18 vs } \\
\text { SGDP 2017-18) }\end{array}$} \\
\hline & 2015-16 & 2017-18 & $\begin{array}{l}2015- \\
16\end{array}$ & 2017-18 & \\
\hline Dive data ( $\mathrm{N}$ individuals) & $(N=5)$ & $(N=7)$ & $(\mathrm{N}=3)$ & $(N=4)$ & \\
\hline Last burrow attendance & $\begin{array}{l}29-\text { Feb } \pm \\
34 \mathrm{~d}\end{array}$ & $\begin{array}{l}26-F e b \pm \\
8 \mathrm{~d}\end{array}$ & $\begin{array}{l}\text { 24-Jan } \\
\pm 8 \mathrm{~d}\end{array}$ & $\begin{array}{l}02-\text { Feb } \pm \\
1 \mathrm{~d}\end{array}$ & $U=28, P=0.011$ \\
\hline Departure date & $\begin{array}{l}\text { 02-Mar } \\
\pm 33 \mathrm{~d}\end{array}$ & $\begin{array}{l}27-\text { Feb } \pm \\
11 \mathrm{~d}\end{array}$ & $\begin{array}{l}\text { 28-Jan } \\
\pm 8 \mathrm{~d}\end{array}$ & $\begin{array}{l}03-F e b \pm \\
1 \mathrm{~d}\end{array}$ & $U=28, P=0.010$ \\
\hline $\begin{array}{l}\text { Outward travel duration } \\
\text { (days) }\end{array}$ & $11 \pm 5$ & $15 \pm 4$ & $9 \pm 2$ & $6 \pm 1$ & $U=28, P=0.009$ \\
\hline $\begin{array}{l}\text { Post-breeding migration } \\
\text { duration (days) }\end{array}$ & - & $207 \pm 15$ & - & $242 \pm 5$ & $U=8, P=0.022$ \\
\hline $\begin{array}{l}\text { Inward travel duration } \\
\text { (days) }\end{array}$ & - & $7 \pm 4$ & - & $24 \pm 3$ & $U=8, P=0.022$ \\
\hline Return date & - & $\begin{array}{l}23-\operatorname{Sep} \pm \\
8 \mathrm{~d}\end{array}$ & - & $\begin{array}{l}03-0 c t \pm \\
6 \mathrm{~d}\end{array}$ & $U=2, P=0.051$ \\
\hline First burrow attendance & - & $\begin{array}{l}\text { 25-Sep } \pm \\
9 \mathrm{~d}\end{array}$ & - & $\begin{array}{l}05-0 c t \pm \\
5 \mathrm{~d}\end{array}$ & $U=3, P=0.104$ \\
\hline Maximum range $(\mathrm{km})$ & - & $\begin{array}{l}2514 \pm \\
273\end{array}$ & - & $\begin{array}{l}3953 \pm \\
507\end{array}$ & $U=8, P=0.017$ \\
\hline $\begin{array}{l}\text { Total distance travelled } \\
(\mathrm{km})\end{array}$ & - & $\begin{array}{l}44232 \pm \\
5869\end{array}$ & - & $\begin{array}{l}88220 \pm \\
9165\end{array}$ & $U=8, P=0.006$ \\
\hline $\begin{array}{l}\text { Stable isotopes ( } \mathrm{N} \\
\text { individuals) }\end{array}$ & $(n=20)$ & $(n=15)$ & $\begin{array}{l}(n= \\
12)\end{array}$ & $(n=23)$ & \\
\hline Feathers $\delta^{13} \mathrm{C}(\%)$ & $\begin{array}{l}-23.1 \pm \\
1.3\end{array}$ & $\begin{array}{l}-23.2 \pm \\
1.4\end{array}$ & $\begin{array}{l}-21.3 \pm \\
1.3\end{array}$ & $\begin{array}{l}-21.8 \pm \\
0.6\end{array}$ & $U=2389, P=0.191$ \\
\hline Feathers $\delta^{15} \mathrm{~N}(\% \circ)$ & $8.8 \pm 0.9$ & $8.3 \pm 0.7$ & $\begin{array}{l}7.9 \pm \\
2.0\end{array}$ & $6.8 \pm 1.5$ & $U=4360, P<0.001$ \\
\hline
\end{tabular}

\section{Isotopic niche}

During incubation, despite total convex hull areas partially overlapping (Fig. 5), stable isotope values in blood were significantly different between species for $\delta^{13} \mathrm{C}\left(t\right.$-tests: $\left.t_{50.095}=6.391, P<0.001\right)$, but not for $\delta^{15} \mathrm{~N}$ (t-tests: $\left.t_{54.974}=1.371, P=0.175\right)$. While inter-individual variation for SGDP was low (Table S4; Fig. 5), isotopic values of incubating CDP stretched out into two groups: a low value group $\left(\delta^{13} \mathrm{C}<\right.$ 
$-21.5 \%$, and $\delta^{15} \mathrm{~N}<9.5 \%$ ), and a high value group $\left(-21.5<\delta^{13} \mathrm{C}<-17 \%\right.$, and $9.5<\delta^{15} \mathrm{~N}<12.5 \%$ ). The first group, comprising the majority of CDP samples, showed similar $\delta^{13} \mathrm{C}$ values between the two species, but lower $\delta^{15} \mathrm{~N}$ values than SGDP (Fig. 5).

Total convex hull areas did not overlap during chick-rearing, both species fully segregating in their isotopic signatures during this breeding stage (Fig. 5 ; for $\delta^{13} \mathrm{C}, t_{58.359}=22.803, P<0.001 ; \delta^{15} \mathrm{~N}, t_{60.663}=$ 17.648, $P<0.001$ ). All SGDP exhibited low $\delta^{13} \mathrm{C}$ and $\delta^{15} \mathrm{~N}$ values close to those during incubation (Table S4; all $\delta^{13} \mathrm{C}<-21.4 \%$ ond $\delta^{15} \mathrm{~N}<9.3 \%$ ), while CDP showed almost exclusively higher values with $\delta^{13} \mathrm{C}>$ $-20.0 \%$ and $\delta^{15} \mathrm{~N}>10 \%$.

During the non-breeding period (moulting period; Fig. 5), CDP exhibited significantly lower feather $\delta^{13} \mathrm{C}$ values ( $t$-tests: $\left.t_{234.57}=-9.943, P<0.001\right)$ and higher $\delta^{15} \mathrm{~N}$ values than SGDP ( $t$-tests: $t_{166.07}=10.206, P<$ $0.001)$. SGDP had a larger range of $\delta^{15} \mathrm{~N}$ values than CDP, including a group of low values $(<5.0 \%$ ). Conversely, both species had few outliers that were characterized by both high $\delta^{13} \mathrm{C}(>-20 \%)$ and $\delta^{15} \mathrm{~N}(>$ $11 \%$ ) values (Fig. 5).

\section{Discussion}

This study provides unique insights into the niche segregation of two congeneric species throughout their whole annual cycle, by combining at-sea movement, diving, accelerometer, and isotopic datasets. The degree of partitioning was highly stage-dependent, emphasized by the complete niche segregation between CDP and SGDP during the chick-rearing period (Table 3). Such seasonal variation supports the hypothesis that resource partitioning between sympatric similar species increases during energetically demanding periods. The variation between breeding stages was likely related to differences in the processes involved in niche segregation, such as competitive exclusion or niche specialization. In postbreeding, the complete separated migration paths and overwintering grounds of CDP and SGDP may involve processes other than inter-species niche segregation, such as past evolutionary divergence. 
Table 3

Summary of spatial (at-sea distribution and dive depth) and trophic segregation between common (CDP) and South-Georgian (SGDP) diving petrels from Kerguelen Islands during the whole annual cycle. The degree of segregation is symbolized as a gradient from no segregation $(-)$ to strong segregation $(+++)$.

\begin{tabular}{|c|c|c|c|}
\hline & & $\begin{array}{l}\text { Degree of } \\
\text { segregation }\end{array}$ & Comment \\
\hline \multirow{4}{*}{$\begin{array}{l}\text { Pre- } \\
\text { breeding }\end{array}$} & Distribution & - & Overlapping (both species off-shore) \\
\hline & Dive depth & & No data \\
\hline & $\delta^{13} \mathrm{C}(\%)$ & & No data \\
\hline & $\delta^{15} \mathrm{~N}(\%)$ & & No data \\
\hline \multirow[t]{4}{*}{ Incubation } & Distribution & - & $\begin{array}{l}\text { Overlapping (both species mostly foraging off- } \\
\text { shore) }\end{array}$ \\
\hline & Dive depth & - & $\mathrm{CDP}=\mathrm{SGDP}$ \\
\hline & $\delta^{13} \mathrm{C}(\%)$ & + & Large distribution of values for CDP \\
\hline & $\delta^{15} \mathrm{~N}(\%)$ & + & For similar $\delta^{13} \mathrm{C}, \mathrm{CDP}<\mathrm{SGDP}$ \\
\hline \multirow{4}{*}{$\begin{array}{l}\text { Chick- } \\
\text { rearing }\end{array}$} & Distribution & +++ & Full spatial segregation (CDP foraging inshore) \\
\hline & Dive depth & +++ & CDP $\gg$ SGDP \\
\hline & $\delta^{13} \mathrm{C}(\%)$ & +++ & CDP $\gg$ SGDP \\
\hline & $\delta^{15} \mathrm{~N}(\%)$ & +++ & CDP $\gg$ SGDP \\
\hline \multirow{4}{*}{$\begin{array}{l}\text { Post- } \\
\text { breeding }\end{array}$} & Distribution & +++ & Full segregation (latitudinal and longitudinal) \\
\hline & Dive depth & & No data \\
\hline & $\delta^{13} \mathrm{C}(\% \circ)$ & ++ & $\mathrm{CDP}<\mathrm{SGDP}$ \\
\hline & $\delta^{15} \mathrm{~N}(\% \circ)$ & ++ & $\mathrm{CDP}>\mathrm{SGDP}$ \\
\hline
\end{tabular}

\section{Phenology: influence of oceanographic conditions}

In the present study, SGDP started breeding 2-3 weeks earlier than CDP, which was in accordance with historical data from the study site (Weimerskirch et al. 1989). However, this marginal allochrony is inconsistent with the general pattern observed elsewhere in the Southern Ocean (e.g. South-Georgia, Crozet and Kerguelen offshore islands), where CDP typically begin breeding slightly earlier than SGDP (Fig. 1). Timing of breeding is a species/population specific life history trait (Perrins 1970), expected to be synchronized with optimal environmental conditions according to the species ecology. The similar phenology of SGDP populations throughout the species distribution highlights a preference for foraging in offshore waters, where the timing of maximum productivity is constant at a large spatial scale (Labat 
et al. 2005). Conversely, the substantial variation in the phenology of CDP at both large and local scales (Weimerskirch et al. 1989; Fromant et al. 2020b), may be driven by a stronger influence of local inshore conditions (Weimerskirch et al. 1989).

Interspecific differences in timing of breeding can also be interpreted as a mechanism to reduce competition between ecological similar species (Granroth-Wilding and Phillips 2019). Nevertheless, the relatively long incubation duration of CDP tends to extend the period during which both species share the same foraging area (i.e. during both the incubation and the early chick-rearing periods of SGDP). This, in addition to the important inconsistencies between breeding sites, downplays the importance of such slight allochrony as a competition avoidance induced mechanism.

\section{Incomplete segregation in the early breeding period: competitive exclusion theory}

Both CDP and SGDP shared similar pelagic foraging areas during the pre-breeding and incubation periods. For both species, the similarity was emphasized by a clear shift in foraging area from the northeast part of the Kerguelen Plateau in pre-breeding, to the south during the incubation period. Such habitat switching between pre-breeding and incubation is common within seabirds (Cherel et al. 2014; Quillfeldt et al. 2020) and is likely to be related to the limited range that a diving petrel can reach between two incubation shifts (1-3 d; Fromant et al. 2021). As central place foragers, breeding seabirds must find a trade-off between performing short enough foraging trips and accessing productive areas. While the north-eastern sector of the Kerguelen Plateau is highly productive (Blain et al. 2007), its distant location (500-800 km from the study colonies) may force CDP and SGDP to exploit a closer foraging area, matching the requirements of undertaking short incubation shifts.

The exploitation of waters along the south-western shelf-slopes by both species during incubation was characterized by similar trip parameters (trip duration, distance travelled and dive depths). However, and despite large overlap in their isotopic niche, stable isotope analyses revealed subtle trophic differences. For similar values of $\delta^{13} \mathrm{C}$ (proxy indicating similar water mass), SGDP exhibited slightly higher $\delta^{15} \mathrm{~N}$ values than CDP suggesting that both species may partially differ in their targeted prey. Although both diving petrel species are known to feed on pelagic euphausiid and copepods species (Bocher et al. 2000), the knowledge of their diet during the incubation period is still limited.

During the incubation period, in addition to the difference in blood $\delta^{15} \mathrm{~N}$ values, SGDP exhibited higher diving effort (higher mean VeDBA) than CDP, despite similar dive characteristics (dive depth and duration). The exploitative competition theory (Wootton 1994) predicts that the larger species (CDP) forages more efficiently, thus outcompeting and excluding the smaller one (SGDP). The larger species occupies the niche where intake rates are highest while minimizing diving effort, whereas the smaller species is constrained to increase its diving effort to catch any other available high-quality food. In the scenario where both species target and forage on similar prey patches, the higher effort observed in SGDP imply that they must swim harder to access remaining prey. To supplement their intake under 
competition, SGDP may need to forage on larger prey that are potentially harder to catch, resulting in the observed higher blood $\delta^{15} \mathrm{~N}$ values and diving effort when compared to CDP. In addition, when the two species fully segregate during the chick-rearing period (see next section), SGDP occupy the niche left vacant by CDP. In particular, this is illustrated by the shift of SGDP isotopic niche towards the niche previously occupied by CDP, supporting the exploitative competition hypothesis.

In South Georgia, the co-existence of CDP and SGDP appears to induce similar exploitative competition during the incubation period, with an isotopic niche segregation arising from SGDP constrained to diving deeper than CDP (Navarro et al. 2014). Similar to Kerguelen, this potential inter-specific competition may result in SGDP pushing the trade-off between prey size and catch towards larger prey (Reid et al. 1997), which would be facilitated by their wider bill compared to CDP (Trallero et al. 2019). However, while body size difference appears to be the main factor driving competitive exclusion, and has been largely documented in various cases in both terrestrial and marine environments (Wearmouth and Sims 2008), our understanding of such predator-prey interactions will remain unclear without direct observation of foraging behaviour in the field.

\section{Complete niche segregation in chick-rearing: niche specialization theory}

During the chick-rearing period, CDP and SGDP fully differed in their at-sea distribution, diving behavior and isotopic niche. This substantial change in the degree of segregation between the two species was driven by a drastic shift in CDP foraging ecology. While SGDP foraged in similar offshore areas and depths during both the incubation and chick-rearing periods, CDP foraging habitat during chick-rearing was restricted to the coastal area (Golfe du Morbihan), switching from open ocean to a semi-closed embayment. This resulted in a substantial decrease in trip duration and distance travelled than during incubation, and when compared to both the incubation and chick-rearing periods of SGDP. This profound shift in at-sea distribution of CDP during the chick-rearing period coincided with substantial modifications in their diving behaviour (increased depth, duration and mean VeDBA per dive).

The change in foraging niche occupied by CDP during the incubation and chick-rearing periods is further supported by the substantial shift in isotopic niche. This complete spatial and isotopic niche segregation has been previously illustrated by stomach content analyses, showing that CDP rely mostly on the swarming amphipod Themisto gaudichaudii during this period (Bocher et al. 2000). In the Golfe du Morbihan, this crustacean displays a strong seasonal variation with a peak of abundance in summer (Labat et al. 2005), precisely matching the chick-rearing period of CDP. As income breeders (Chastel et al. 1995), diving petrels are expected to match the energy-demanding chick-rearing period with a peak of resource availability (Perrins 1970). Thus, it is likely that the observed switch in CDP foraging habitat between incubation and chick-rearing is triggered by the summer high density of T. gaudichaudii in the Golfe du Morbihan (Bocher et al. 2001).

In addition, the overall pattern of isotopic values shifting from offshore to inshore environments between incubation and chick-rearing masks the fact that some CDP individuals already started feeding in the 
Golfe du Morbihan while still incubating. This suggests that CDP switched foraging behaviour as soon as T. gaudichaudii became available within the gulf. Such results may provide key information to understand the process of niche segregation between CDP and SGDP. Indeed, surprisingly, SGDP did not appear to take advantage of this reliable and locally superabundant prey during neither the incubation period nor the energetically demanding chick-rearing period.

Spatial and trophic segregations are considered to result from competitive exclusion (the bigger species accessing the best resource), or niche specialization (induced by morphological and/or physiological differences) (Phillips et al. 2004). Although, both processes may be applicable in the present case, the total absence of SGDP from the T. gaudichaudii niche strongly suggests partitioning arising from physical capabilities and diving performance. Indeed, for a breath-hold diving species, maximum dive depth and duration generally increase with body mass (Schreer and Kovacs 1997), while prey capture is proportional to the time that an individual allocates to the bottom phase of a dive (Wilson 2010). Following the model of depth/time relative efficiency developed by Wilson (2010), CDP appears to be the most efficient of the two species at depths in excess of $10 \mathrm{~m}$.

The relative absence of surface feeders in the Golfe du Morbihan (Bocher et al. 2001; Cherel et al. 2014), in addition to the depths exploited by CDP and coastal penguin species feeding on T. gaudichaudii (Bocher et al. 2000, 2001), confirm that this abundant prey is mainly restricted to depths deeper than 10 $\mathrm{m}$. Therefore, the relatively lower efficiency of SGDP at deeper depths, associated with their smaller body size, may restrict their access to T. gaudichaudii in the Golfe du Morbihan. Although SGDP are able to dive as deep as $20 \mathrm{~m}$, when compared to CDP for similar dive depth and duration, the higher mean VeDBA observed for SGDP suggests these individuals have a lower diving capacity.

In addition, the lower wing loading of SGDP may also reflect their adaptation to flying over longer distances than CDP (Thaxter et al. 2010). Notable differences in diving performances and energetic expenditure of the SGDP appear to be key factors explaining the use of distant areas to target more accessible prey species at shallower depth. For SGDP, the energetic cost of repeated deep and long dives may exceed the cost of undertaking longer trips but foraging on more accessible prey in conditions of limited exploitative competition. Therefore, the complete niche segregation observed between CDP and SGDP during the chick-rearing period may result from niche specialization and not direct competition.

At South Georgia, Reid et al. (1997) reached the same conclusions based on stomach content analyses of both species during the chick-rearing period, interpreting the difference in targeted prey as differential diving capabilities. In the extensive literature exploring niche partitioning between similar species or sex, niche specialization commonly originates from body size differences and divergent relative efficiencies to exploit the environment (Wearmouth and Sims 2008). For example, the between-sex difference in wing loading for albatrosses may advantage females in lower wind conditions (Phillips et al. 2011), which ultimately appears to induce latitudinal habitat specialization (Weimerskirch et al. 1997; Phillips et al. 2004). Similarly, niche segregation in alcids during the chick-rearing period appears to be caused by differential flying and/or diving capabilities (Thaxter et al. 2010). 


\section{Post-breeding migration: historical distribution and congeneric segregation}

During the inter-breeding period, CDP and SGDP headed in divergent directions and different latitudes. The stable isotopic signatures in body feathers supported the idea of latitudinal segregation, with lower $\delta^{13} \mathrm{C}$ values for CDP indicating a moulting area farther south than for SGDP (Jaeger et al. 2010). Adult diving petrels migrate to wintering areas directly after the end of the breeding season (Rayner et al. 2017; Fromant et al. 2020b), and renew their plumage during the first months of this period (Fromant et al. 2020b). Because moult is an energetically/nutritional demanding process, seabirds are likely to renew their plumage where the surrounding waters are productive (Cherel et al. 2016), which may incite ecologically similar species to migrate to different areas. Previous studies on winter distribution of small petrels and prions showed clear inter-species latitudinal segregation, which was explained by differences in preferred water masses (Quillfeldt et al. 2015).

Interestingly, the recent studies investigating the post-breeding distribution of three different diving petrel species (Navarro et al. 2015; Rayner et al. 2017; Fromant et al. 2020b; Fischer et al. 2021; present study) all revealed that diving petrels migrate to well defined population/species-specific areas. This contrasts with the highly dispersive behavior generally observed with other small-sized procellariiform species (Quillfeldt et al. 2015; Navarro et al. 2015). In particular, the ecological theory of segregation predicts that individuals should disperse when they are no longer tied to their breeding grounds. Therefore, the observed segregation in migration area may not be a response to the selective pressure arising from present competition avoidance between sympatric species, but instead, could reflect past evolutionary divergence (Peck-Richardson et al. 2018). Divergent but consistent species-based and population-based cultural patterns may suggest that each species/population is responding to different life history traits. The evolution of wintering ecological optimum for each species/population may, therefore, involve historical distribution shift of water masses but also the sequence of colonization(s) and speciation within diving petrels.

In addition, by heading south-east, Kerguelen SGDP may as well segregate from large populations of conspecifics breeding on Crozet Islands. Two species can indeed segregate in other dimensions than space when their distribution overlaps, while two synchronous populations of the same species must segregate spatially in order to avoid competition for the same resource. Thus, perceived inter-breeding segregation between sympatric sibling species could rather result from intra-species (populations) competition avoidance.

\section{Conclusion}

Overall, the present study demonstrates the importance of integrating approaches from different fields (foraging and trophic ecology, ecophysiology, phenology and morphometry) to describe the co-existence of ecologically similar species. The degree of partitioning and the mechanisms involved were highly stage-dependent, allowing a better understanding in the coexistence of large populations of two sibling 
seabird species. Although any study of niche segregation is only a snapshot of a continuous process, such results point to multiple, non-exclusive causal factors of niche segregation. The evolution of species optimum through competition may have lead SGDP to exploit a niche where CDP are absent or rarely present (as seen during the incubation period). Alternatively, and/or both species have evolved separately, and developed different capacities/preferences related to their optimal environment (such as the segregation observed during the chick-rearing and post-breeding period). In the context of climate change, the fragile equilibrium between species living in sympatry is likely to be modified, and, with the evolution of their ecosystems, their niche is going to change accordingly. Investigating the ecology and niche segregation of ubiquitous species experiencing rapid environmental modifications throughout their whole distribution is, therefore, fundamental to fully understand the short and long-term effects of climate change.

\section{Declarations}

\section{Acknowledgments}

We thank the IPEV logistic staff (Y. Le Meur, N. Marchand, R. Bellec, and the Geners of the 66-70 missions on Kerguelen) for their constant support, and the numerous field technicians who collected data over the five field seasons (J. Laborie, S. Peroteau, E. Debenest, J. Fleureau, U. Courcoux-Caro, and T. Getti). We thank G. Guillou from the PAI of the LIENSs laboratory for running stable isotope analyses, and the SAB du CEBC, and especially C. Ribout for expertise and technical help in seabird molecular sexing. The Institut Universitaire de France is acknowledged for its support to PB as a Senior Member.

Funding: This study was funded by the French Polar Institute IPEV (Programs IPEV 394 (resp. C.A Bost) \& 109 (resp. H. Weimerskirch).

Conflict of interest: The authors declare that they have no conflict of interest.

Ethics approval: All animal handling and instrumentation was approved by the Ethical Committee of the Terres Australes et Antarctiques Francaises.

Consent to participate: Not applicable

Consent for publication: Not applicable

Availability of data and material: Our data are available within the Dryad Digital Repository: https://datadryad.org/stash/share/RLL_JzEDtHvSrHBxFIp8vLP5LAnOKULj-JOpeARG8tA

Code availability: Not applicable

\section{References}


1. Ainley DG, Dugger KD, Ford RG, et al. (2009) Association of predators and prey at frontal features in the California current: competition, facilitation, and co-occurrence. Mar Ecol Prog Ser 389:271-94.

2. Barger CP, Young RC, Will A, Ito M, Kitaysky AS (2016) Resource partitioning between sympatric seabird species increases during chick-rearing. Ecosphere 7(9):e01447.

3. Barger CP, Kitaysky AS (2012) Isotopic segregation between sympatric seabird species increases with nutritional stress. Biol Lett 8:442-445.

4. Blain S, Quéguiner B, Armand L et al. (2007) Effect of natural iron fertilization on carbon sequestration in the Southern Ocean. Nature 446:1070-1074.

5. Bocher P, Cherel Y, Hobson KA (2000) Complete trophic segregation between South Georgian and common diving petrels during breeding at lles Kerguelen. Mar Ecol Prog Ser 208:249-264.

6. Bocher P, Cherel Y, Labat JP, Mayzaud P, Razouls S, Jouventin P (2001) Amphipod-based food web: Themisto gaudichaudii caught in nets and by seabirds in Kerguelen waters, southern Indian Ocean. Mar Ecol Prog Ser 223:261-276.

7. Bolker B, Skaug H, Magnusson A, Nielsen A (2012) Getting started with the g/mmADMB package.

8. Calado JG, Matos DM, Ramos JA, et al. (2018) Seasonal and annual differences in the foraging ecology of two gull species breeding in sympatry and their use of fishery discards. J Avian Biol 49(1):e01463.

9. Calenge $C$ (2006) The package adehabitat for the $R$ software: a tool for the analysis of space and habitat use by animals. Ecol Modell 197:516-519.

10. Chastel O, Weimerskirch $\mathrm{H}$, Jouventin P (1995) Body condition and seabird reproductive performance: a study of three petrel species. Ecology 76:2240-2246.

11. Cherel Y, Hobson KA, Weimerskirch H (2000) Using stable-isotope analysis of feathers to distinguish moulting and breeding origins of seabirds. Oecologia 122:155-162.

12. Cherel $\mathrm{Y}$, Hobson KA, Weimerskirch $\mathrm{H}$ (2005) Using stable isotopes to study resource acquisition and allocation in procellariform seabirds. Oecologia 145:533-540.

13. Cherel Y, Connan M, Jaeger A, Richard P (2014) Seabird year-round and historical feeding ecology: blood and feather $\delta 13 \mathrm{C}$ and $\delta 15 \mathrm{~N}$ values document foraging plasticity of small sympatric petrels. Mar Ecol Prog Ser 505:267-280.

14. Cherel Y, Quillfeldt P, Delord K, Weimerskirch H (2016) Combination of at-sea activity, geolocation and feather stable isotopes documents where and when seabirds molt. Front Ecol Evol 4:3.

15. Dunn RE, Wanless S, Green JA, Harris MP, Daunt F (2019) Effects of body size, sex, parental care and moult strategies on auk diving behaviour outside the breeding season. J Avian Biol 50(7):e02012.

16. Eizenberg YH, Fromant A, Lec'hvien A, Arnould JP (2021) Contrasting impacts of environmental variability on the breeding biology of two sympatric small procellariiform seabirds in south-eastern Australia. PLoS ONE 16(9):e0250916.

17. Fieberg J, Kochanny CO (2005) Quantifying home-range overlap: the importance of the utilization distribution. J Wildl Manage 69(4):1346-1359. 
18. Finke DL, Snyder WE (2008) Niche partitioning increases resource exploitation by diverse communities. Science 321:1488-1490.

19. Fischer JH, Debski I, Miskelly CM, et al. (2018) Analyses of phenotypic differentiations among South Georgian Diving Petrel (Pelecanoides georgicus) populations reveal an undescribed and highly endangered species from New Zealand. PLoS One 13(6):e0197766.

20. Fischer JH, Debski I, Spitz DB, Taylor GA, Wittmer HU (2021) Year-round offshore distribution, behaviour, and overlap with commercial fisheries of a Critically Endangered small petrel. Mar Ecol Prog Ser 660:171-187.

21. Fromant A, Miskelly CM, Arnould JPY, Bost CA (2020a) Artificial burrows as a tool for long-term studies of diving petrels. Polar Biol 43(5):435-442.

22. Fromant A, Bost CA, Bustamante P, et al. (2020b) Temporal and spatial differences in the postbreeding behaviour of a ubiquitous Southern Hemisphere seabird, the common diving petrel. R Soc Open Sci 7(11):200670.

23. Fromant A, Delord K, Bost CA, et al. (2021) Impact of extreme environmental conditions: foraging behaviour and trophic ecology responses of a diving seabird, the common diving petrel. Prog Oceanogr 198:102676.

24. Granroth-Wilding HM, Phillips RA (2019) Segregation in space and time explains the coexistence of two sympatric sub-Antarctic petrels. Ibis 161(1):101-16.

25. Hutchinson GE (1957) Concluding remarks. Cold Spring Harbor Symp 22:415-427.

26. Jackson AL, Inger R, Parnell AC, Bearhop S (2011) Comparing isotopic niche widths among and within communities: SIBER-Stable Isotope Bayesian Ellipses in R. J Anim Ecol 80(3):595-602.

27. Jaeger A, Lecomte VJ, Weimerskirch H, Richard P, Cherel Y (2010) Seabird satellite tracking validates the use of latitudinal isoscapes to depict predators' foraging areas in the Southern Ocean. Rapid Commun Mass Spectrom 24:3456-3460.

28. Jouventin P, Mougin JL, Stahl JC, Weimerskirch H (1985) Comparative biology of the burrowing petrels of the Crozet Islands. Notornis 32:157-220.

29. Kokubun N, Yamamoto T, Sato N, Watanuki Y, et al. (2016) Foraging segregation of two congeneric diving seabird species breeding on St. George Island, Bering Sea. Biogeosciences 13(8):2579-2591.

30. Labat JP, Mayzaud P, Sabini S (2005) Population dynamics of Themisto gaudichaudii in Kerguelen islands waters, Southern Indian Ocean. Polar Biol 28:776-83.

31. Latham J (1999) Interspecific interactions of ungulates in European forests: an overview. For Ecol Manag 120:13-21.

32. MacArthur RH (1958) Population ecology of some warblers of north-eastern coniferous forests. Ecology 39:599-619.

33. Marchant S, Higgins PJ (1990) Handbook of Australian, New Zealand and Antarctic birds. Melbourne, Australia: Oxford University Press. 
34. Monson RK, Littlejohn RO, Williams GJ (1983) Photosynthetic adaptation to temperature in four species from the Colorado shortgrass steppe: a physiological model of coexistence. Oecologia 58:43-51.

35. Navarro J, Votier SC, Aguzzi J, Chiesa J, Forero MG, Phillips RA (2013) Ecological segregation in space, time and trophic niche of sympatric planktivorous petrels. PloS One 8(4):e62897.

36. Navarro J, Votier SC, Phillips RA (2014) Diving capabilities of diving petrels. Polar Biol 37(6):897901.

37. Navarro J, Cardador L, Brown R, Phillips RA (2015) Spatial distribution and ecological niches of nonbreeding planktivorous petrels. Sci Rep 5(1):1-5.

38. Payne MR, Prince PA (1979) Identification and breeding biology of the diving petrels Pelecanoides georgicus and P. urinatrix exsul at South Georgia. N Z J Zoo 6(2):299-318.

39. Peck-Richardson AG, Lyons DE, Roby DD, Cushing DA, Lerczak JA (2018) Three-dimensional foraging habitat use and niche partitioning in two sympatric seabird species, Phalacrocorax auritus and $P$. penicillatus. Mar Ecol Prog Ser 586:251-64.

40. Perrins CM (1970) Timing of birds breeding seasons. Ibis 112:242-255.

41. Phillips RA, Silk JRD, Phalan B, Catry P, Croxall JP (2004) Seasonal sexual segregation in two Thalassarche albatross species: competitive exclusion, reproductive role specialization or foraging niche divergence? Proc Royal Soc B 271(1545):1283-1291.

42. Phillips RA, McGill RA, Dawson DA, Bearhop S (2011) Sexual segregation in distribution, diet and trophic level of seabirds: insights from stable isotope analysis. Mar Biol 158(10):2199-208.

43. Putman R, Flueck WT (2011) Intraspecific variation in biology and ecology of deer: magnitude and causation. Anim Prod Sci 51:277-291.

44. Quillfeldt P, Cherel Y, Delord K, Weimerkirch H (2015) Cool, cold or colder? Spatial segregation of prions and blue petrels is explained by differences in preferred sea surface temperatures. Biol Lett 11:20141090.

45. Quillfeldt P, Weimerskirch $H$, Delord K, Cherel $Y$ (2020) Niche switching and leapfrog foraging: movement ecology of sympatric petrels during the early breeding season. Mov Ecol 8:1-14.

46. R Development Core Team. 2020 R: a language and environment for statistical computing, reference index version 2.12.2.

47. Rayner MJ, Taylor GA, Gaskin CP, Dunphy BJ (2017) Seasonal activity and unpredicted polar front migration of northern New Zealand common diving petrels (Pelecanoides urinatrix). Emu 117(3):290-298.

48. Reid K, Croxall JP, Edwards TM, Hill HJ, Prince PA (1997) Diet and feeding ecology of the diving petrels Pelecanoides georgicus and P. urinatrix at South Georgia. Polar Biol 17(2):17-24.

49. Ridoux V (1994) The diets and dietary segregation of seabirds at the subantarctic Crozet Islands. Mar Ornithol 22:65-128. 
50. Schreer JF, Kovacs KM (1997) Allometry of diving capacity in air-breathing vertebrates. Can J Zool 75(3):339-358.

51. Thaxter $C B$, Wanless $S$, Daunt $F$, et al. (2010) Influence of wing loading on the trade-off between pursuit-diving and flight in common guillemots and razorbills. J Exp Biol 213(7):1018-25.

52. Trallero L, Farré M, Phillips RA, Navarro J (2019) Geometric morphometrics reveal interspecific and sexual differences in bill morphology in four sympatric planktivorous petrels. J Zool 307(3):167177.

53. Wearmouth VJ, Sims DW (2008) Sexual segregation in marine fish, reptiles, birds and mammals: behaviour patterns, mechanisms and conservation implications. Adv Mar Biol 54:107-170.

54. Weimerskirch H, Zotier R, Jouventin P (1989) The avifauna of the Kerguelen Islands. Emu 89:15-29.

55. Weimerskirch $H$, Cherel $Y$, Cuenot-Chaillet $F$, Ridoux V (1997) Alternative foraging strategies and resource allocation by male and female wandering albatrosses. Ecology 78:2051-63.

56. Wilson RP (2010) Resource partitioning and niche hyper-volume overlap in free-living pygoscelid penguins. Funct Ecol 24(3):646-657.

57. Wood S (2018) $m g c v$. Mixed GAM computation vehicle with automatic smoothness estimation.

58. Wootton JT (1994) The nature and consequences of indirect effects in ecological communities. Annu Rev Ecol Syst 25:443-466.

59. Zuur AF, leno EN, Elphick CS (2010) A protocol for data exploration to avoid common statistical problems. Methods Ecol Evol 1:3-14.

\section{Figures}



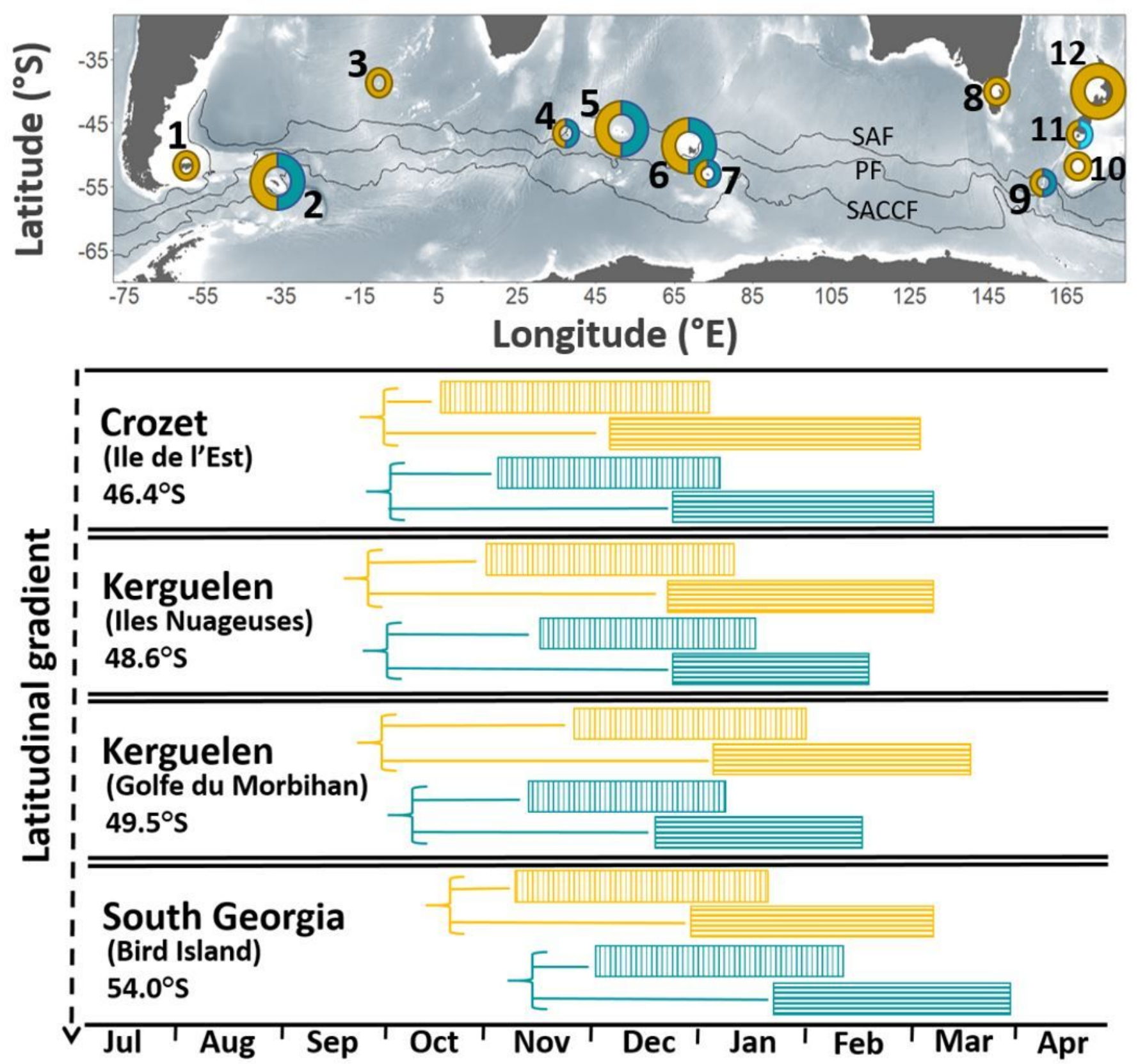

Figure 1

Upper panel: Distribution of common (CDP; yellow) and South Georgian (SGDP; blue) diving petrels. 1: Falklands/Malvinas Islands; 2: South Georgia; 3: Gough/Tristan da Cunha Islands; 4: Prince Edward Islands; 5: Crozet Islands; 6: Kerguelen Islands; 7: Heard/McDonald Islands; 8: south-eastern Australia; 9: Macquarie Island; 10: Auckland/Campbell Islands; 11: Stewart Island islets; 12: New Zealand main islands. Larger circles show populations with more than 500000 individuals of each species (Marchant and Higgins 1990). Shared circles show sympatric populations of CDP and SGDP. Light blue for Stewart Island islets (11) corresponds to Whenua Hou diving petrel (P. whenuahouensis). The black lines represent the approximate location of the Subantarctic Front (SAF), Polar Front (PF) and Southern Antarctic Circumpolar Current Front (SACCF). Lower panel: Phenology of common (yellow) and South Georgian (blue) diving petrels breeding in sympatry. Blocks with vertical lines correspond to incubation, 
and horizontal lines show the chick-rearing period. Horizontal lines indicate the pre-breeding period (from when birds return to the colony to the start of the breeding period). Phenology data were adapted from Jouventin et al. (1985) (Crozet), Weimerskirch et al. (1989) (Kerguelen), and Payne and Prince (1979) and Reid et al. (1997) (South Georgia). For Kerguelen, lle Nuageuses are a group of offshore islands while Golfe du Morbihan is a semi-closed embayment.

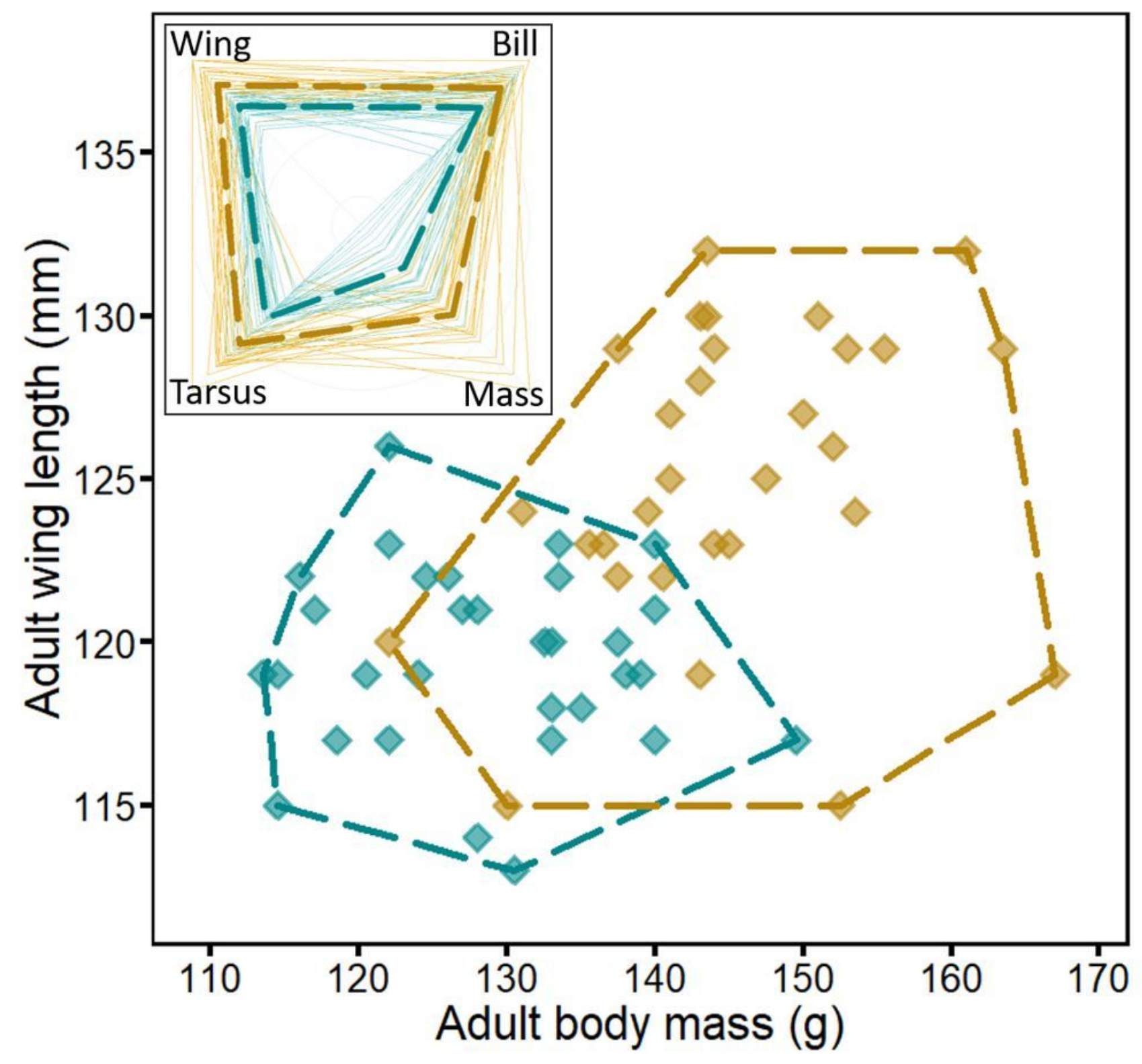

Figure 2

Main panel: morphological differences between adult common (yellow) and South Georgian (blue) diving petrels breeding at Kerguelen Islands. The dashed lines indicate the morphological range of each species. Top left panel: radial chart indicating the intra- and inter-species morphological variations. These are relative values estimated as the proportion of the maximum individual values for both species combined (Value / Maximum Value (CDP : SGDP)). Each faint line corresponds to one individual, and the bold dashed lines correspond to the mean value for each species. 


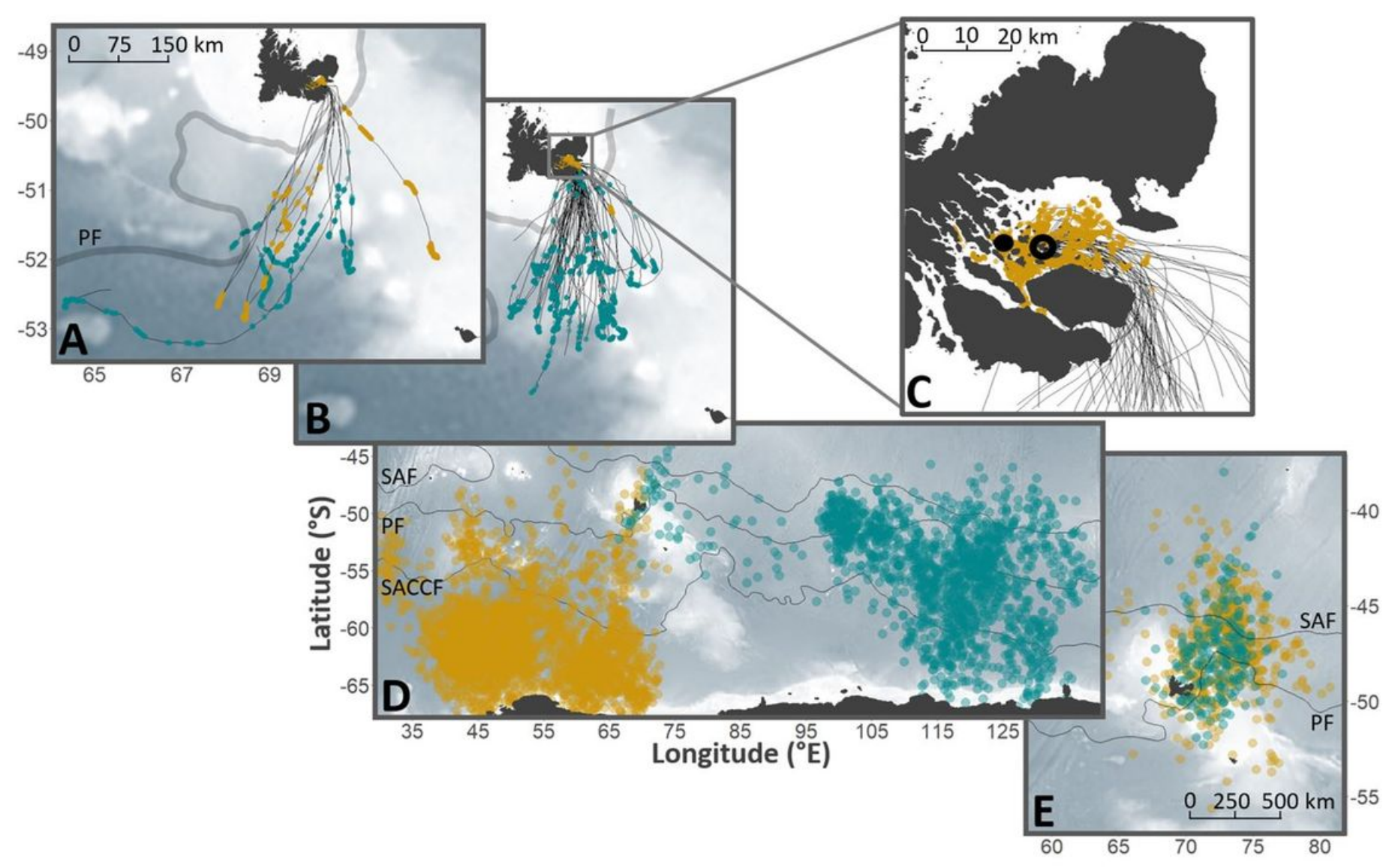

\section{Figure 3}

At-sea distribution of common (yellow) and South Georgian (blue) diving petrels from Kerguelen Islands. Tracks in incubation ( $A$ ) and chick-rearing (B and $C$ ) were collected using GPS, where dots indicate positions with speed $<9.1 \mathrm{~km} \cdot \mathrm{h}-1$ (proxy of foraging locations; see Methods for more details). Data in post-breeding (D) and pre-breeding (E) were collected using GLS (2 locations per day). In panel C, the full black circle indicates the location of lle Mayes where CDP were studied, and the open black circle the location of lle aux Cochons where SGDP were studied. 


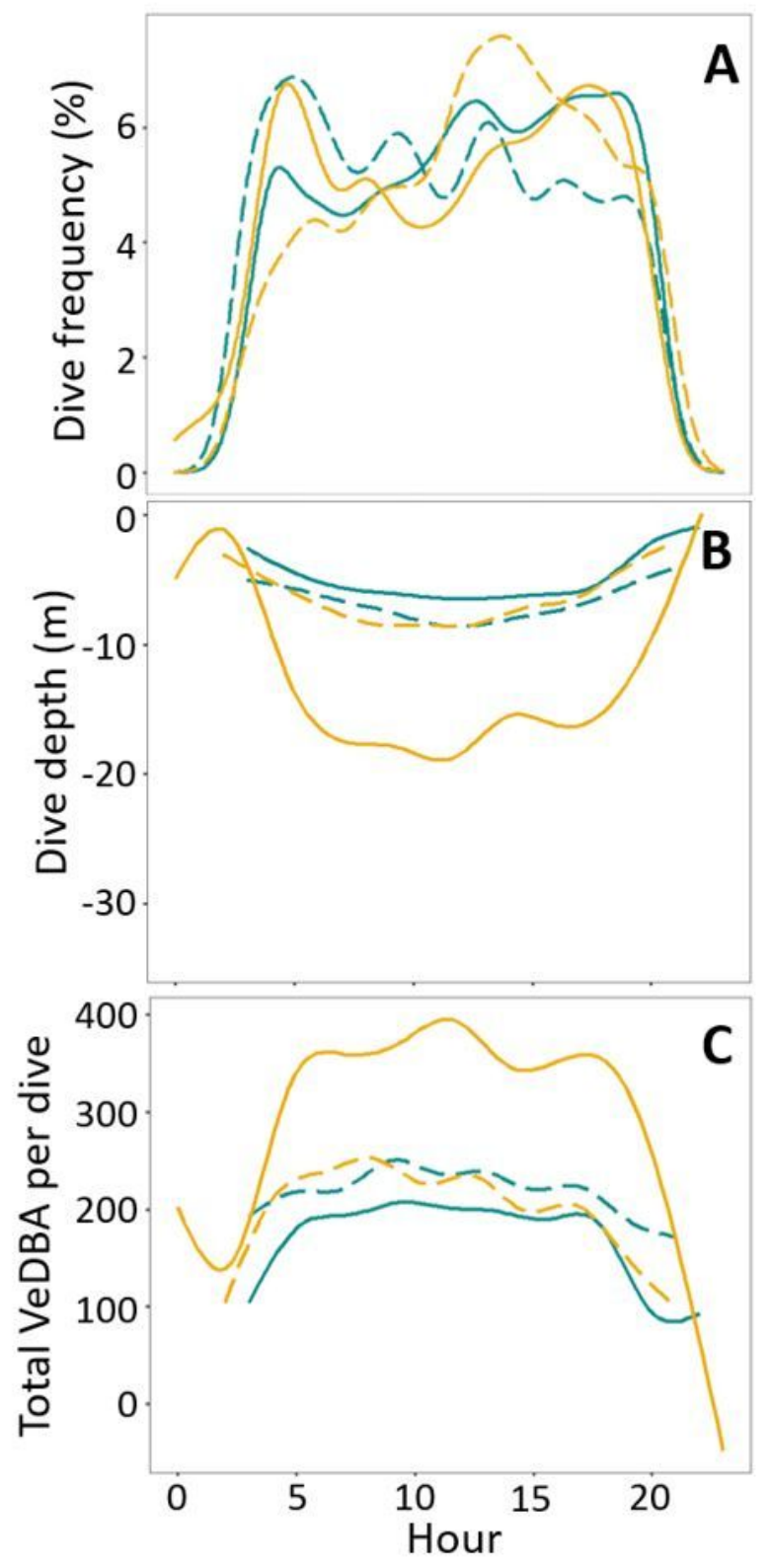

\section{Common} diving petrel

- - Incubation Chick-rearing

\section{South Georgian diving petrel}

- - Incubation

Chick-rearing

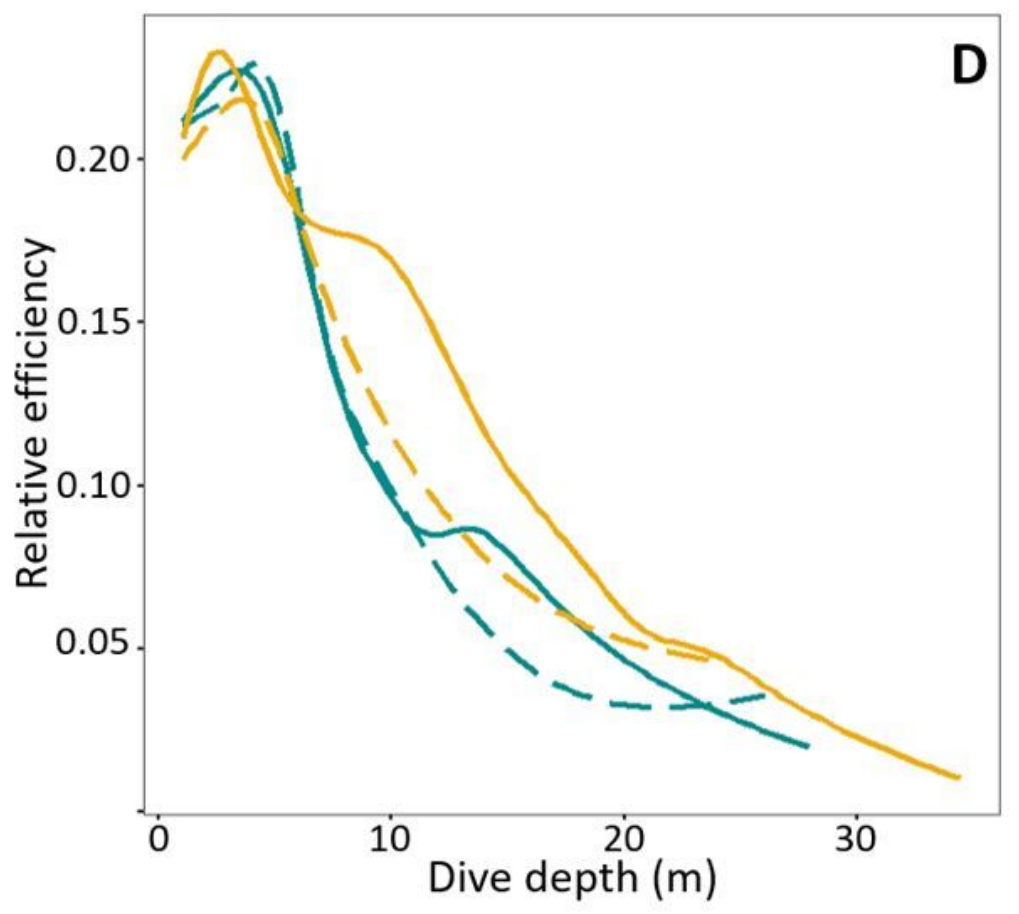

\section{Figure 4}

Hourly variation for dive frequency (A), dive depth (B) and total VeDBA (Vectorial Dynamic Body Acceleration) (C) and relative diving efficiency (Wilson 2010) of common and South Georgian diving petrels during both incubation and chick-rearing periods predicted by generalized additive mixed models. The efficiency is calculated by dividing the duration of the bottom phase by the total time spent during one dive cycle (dive duration + post-dive duration) for that particular depth. 

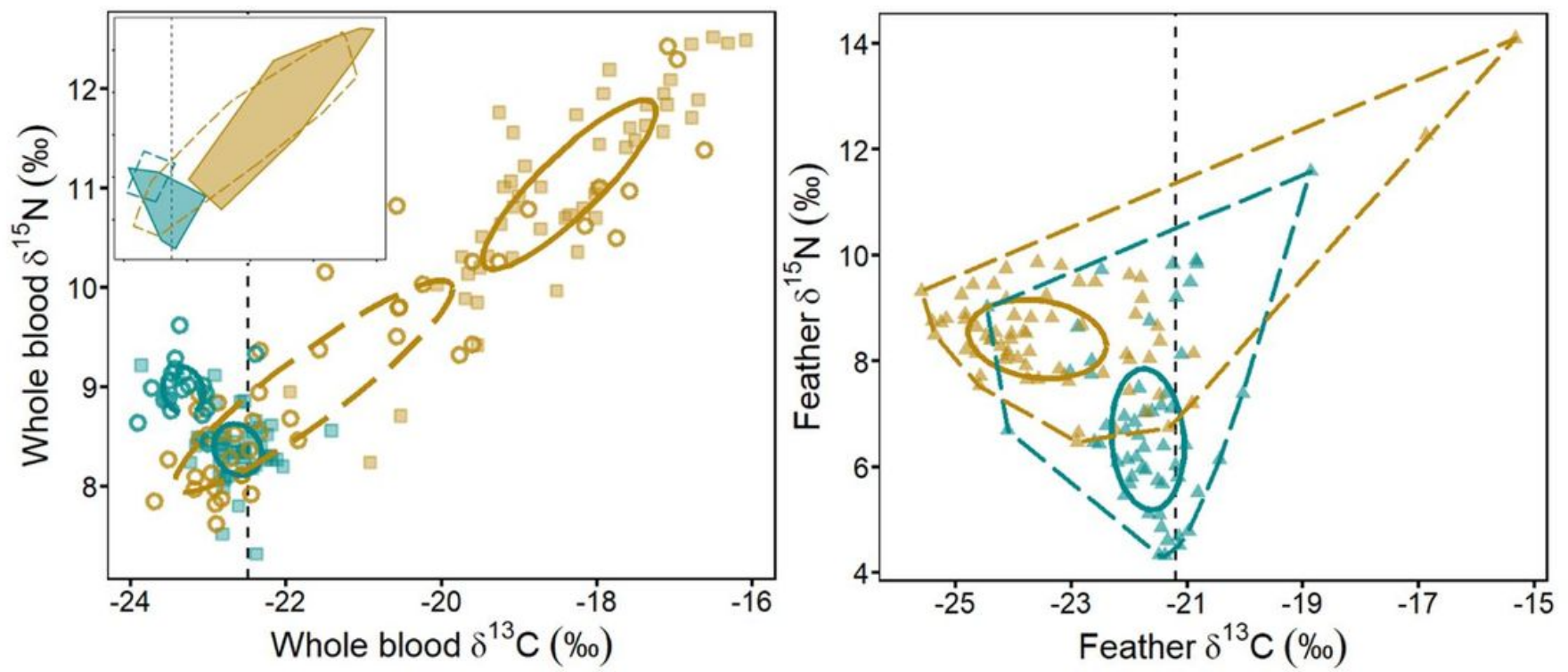

Figure 5

Values of $\delta 13 \mathrm{C}$ and $\delta 15 \mathrm{~N}$ values in blood (left) and feathers (right) of common (yellow) and SouthGeorgian (blue) diving petrels from Kerguelen Islands. Both panels indicate the standard ellipses corrected for sample size (SEAc) and the total convex hull area (total amount of niche space occupied). The left panel corresponds to incubation (open circles, dashed lines) and chick-rearing (full squares, solid lines), with the total convex hull area in the top left panel. The black vertical line corresponds to the value for the Polar Front.

\section{Supplementary Files}

This is a list of supplementary files associated with this preprint. Click to download.

- SupplementaryMaterialNicheSegregationCDPSGDPKerguelen.docx 